WORKROOMS Journal No 2 - July 2014

\title{
Designing Dual-Active Bridge (DAB) Converter for Energy Storage/Recovery Systems in a Lighting Smart Grid context.
}

Rico-Secades, Manuel (http://orcid.org/0000-0002-5372-0330); Garcia-Llera, Daniel (http://orcid.org/0000-0002-1980-9526); Lopez-

Corominas, Emilio (http://orcid.org/0000-0003-3127-7822); Calleja-Rodríguez, Antonio Javier (http://orcid.org/0000-0002-4271-8227)

\begin{abstract}
Lighting Systems are suffering and important evolution with the introduction of LED lighting systems with new strategies of energy savings, incorporation of renewable energy sources and optionally a bidirectional interconnection with the mains (AC grid or DC interconnection bus). Lighting Systems are moving to Lighting Smart Grids and step by step integrating in Smart City strategies. In this context design of modular and efficient energy storage/recovery systems are gaining importance looking for future applications and new services. Thus, this work describes the design procedure of Dual-Active Bridge (DAB) Converter as energy storage/recovery system in the context of a Lighting Smart Grid. A complete study of this converters, design procedure in order to operate over the Optimal Line (no reactive power) and two simplified control strategy (Linear Phase Droop Control - LPDC and Cosine Phase Droop Control -CPDC) have been proposed, introducing in this way a robust design with modular and self-equalization capability.
\end{abstract}

Index Terms — Lighting Smart Grid, Dual-Active Bridge, Renewable Energy, LED lighting, Energy Storage, Smart Cities, Droop Control

(*) All authors are from EPI Gijon - University of Oviedo. Electrical Engineering Department. Campus de Viesques- Building 3 (Phone: +34-985182087 Fax: +34-985182138) - ES-33204 - GIJON - ASTURIAS - SPAIN.

e-mail of authors: Rico-Secades M. (Corresponding author) mrico@uniovi.es, García-Llera D. danielgarciallera@yahoo.com, Corominas E.L. elopez@uniovi.es, Calleja A.J. calleja@uniovi.es 


\section{INTRODUCTION}

Lighting Systems are suffering and important evolution, moving to Lighting Smart Grids (LSG) and open the door to new capabilities and new services to citizens. Different strategies can be adopted thinking in a LSG [1] involving LED drivers, incorporation of renewable energy sources using Maximum Power Point Tracking (MPPT) strategies, capability of grid or DC bus interconnection in order to extract or deliver energy outside the lighting system and, of course, the energy storage/recovery systems focus of this work. All these elements are presented in figure 1 showing a typical LSG with all of this elements.

Each element in the system play a different role and behaviors are predictable or unpredictable depending of external, environmental decision or energy saving strategies. Renewable sources operate with MPPT control, looking for extract as

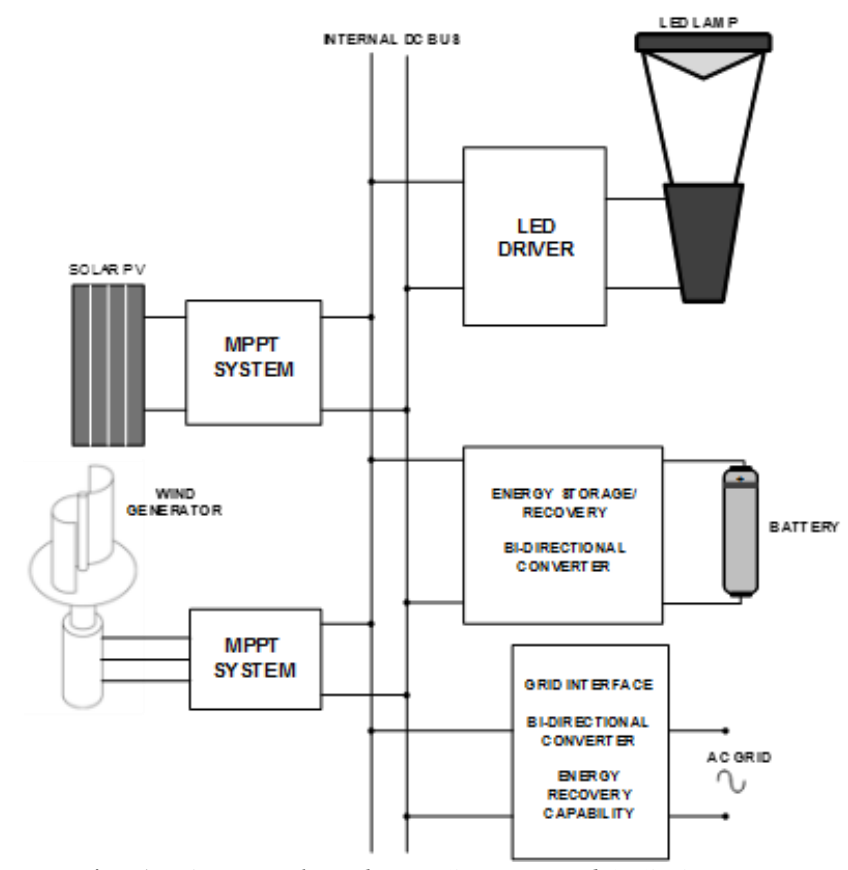

Fig. 1. A typical Lighting Smart Grid (LSG) system.

power as possible from sun, wind or any other renewable source. Power injected to the DC bus is unpredictable and depends on external conditions. On the other hands, LED Lighting Systems represents the Power load, maximum power in known but control strategies depends also in environmental conditions, strategy for energy savings and so on. Also another type of power loads are possible in the context of a Smart City in order to provide new services to citizens (charges for different gadgets, for example).

Interface with mains or DC bus is optional, isolated systems do not incorporate mains interface capability. In any case, power 
injection or extraction may depend of different grids strategies, is controllable but must be considered also as unpredictable.

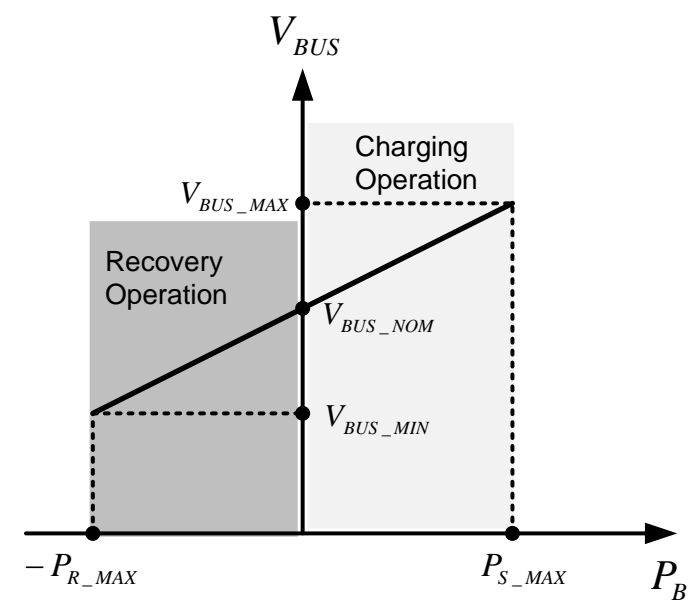

Fig. 2. Design objective of linear Power versus DC bus voltage control strategy for each Energy/Recovery module.

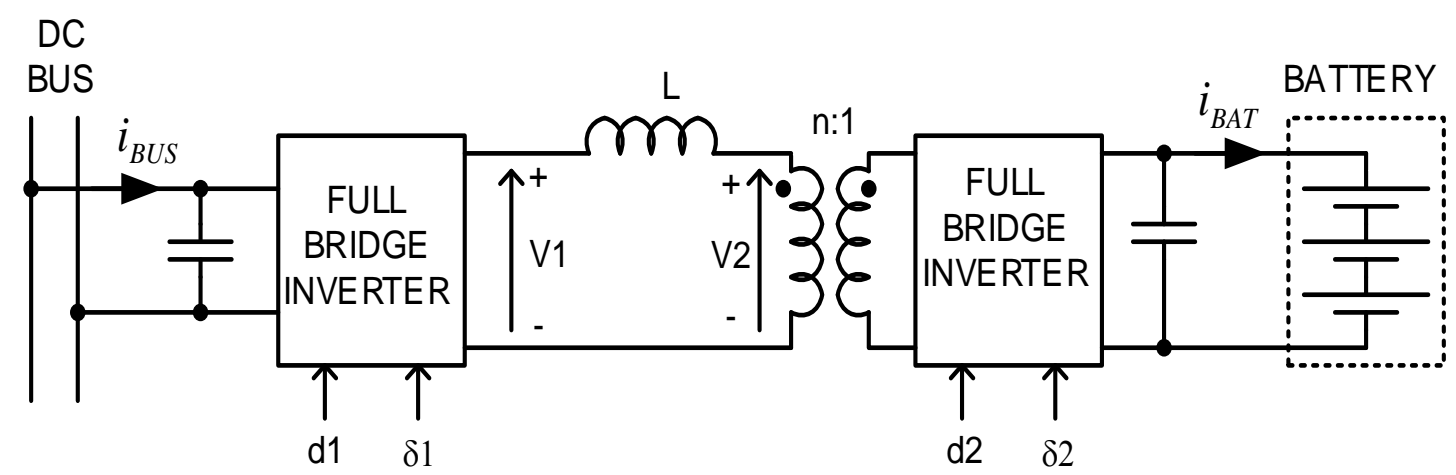

Fig. 3. Basic structure of a Dual Active-Bridge (DAB) bidirectional converter.

In this context, the role of energy storage/recovery system is fundamental. Stabilization of DC bus is the main task of this elements: store or recovery energy depending on system situation. Perfect bus stabilization is possible by means of coordinate operation of all energy storage/recovery modules (master-slave operation and communication between modules is required) but in LSG, with a dedicated internal DC bus, a friendly range of fluctuation of DC bus is possible and simplify design of all elements.

Using strategies of power extracted or injected to or from the DC bus voltage as a function of the voltage value (Droop Control), see figure 2, communications between modules is not required in order to assure a perfect equalization of all energy/storage modules assuring a perfect operation a high level of modularity in the whole system.

This study propose the use of DAB converters as energy storage/system using a easy to implement strategy of simplified Droop Control strategies, denoted as Linear Phase Droop Control (LPDC) and Cosine Phase Droop Control (CPDC). A complete 
study of the DAB converter in order to make compatible LPDC/CPDC strategies with operation over optimal line (not reactive energy and zero current switching in one of the inverters) has been done.

\section{BASIC OPERATION OF THE DUAL-ACTIVE BRIDGE (DAB) CONVERTER}

Figure 3 shows the basic and well-known structure of a DAB converter used in different applications, in this case proposed as a modular energy storage/recovery system for a Lighting Smart Grid. It is a bidirectional converter [2] and it is based in the coordinate operation of two full bridge inverters, one inductor and, optionally, one isolation transformer. Several works deals about DAB converter, reference [2] shows a DC to DC application with output voltage stabilization, introduction of droop control can be found in [3], a comparison among other topologies in [4], a study about switching optimization in [5], implementation in AC-to-DC applications [6] and Home Area Network applications in [7].

Several design strategies can be conducted in order to use this extremely flexible converter. Duty Cycles $\left(\mathrm{d}_{1}\right.$ and $\left.\mathrm{d}_{2}\right)$ and phase shift $\left(\delta_{1}\right.$ and $\left.\delta_{2}\right)$ of both converters can be used as control signals. $\delta_{2}$ is assumed as reference $\left(\delta_{2}=0\right)$ and $\delta_{1}$ represents the phase of waveforms between both inverters $\left(\delta_{1}=\delta\right)$.

Typical waveforms and nomenclature have been included in figure 4 . It is necessary to mention that $d_{1}$ and $d_{2}$ moves from 0 to 1 and phase $\delta$ moves from $-180^{\circ}$ to $+180^{\circ}$ (Negatives values implies $\mathrm{V}_{1}$ voltage delayed with $\mathrm{V}_{2}$ voltage and positive values implies $\mathrm{V}_{1}$ voltage in advance with $\mathrm{V}_{2}$ voltage).

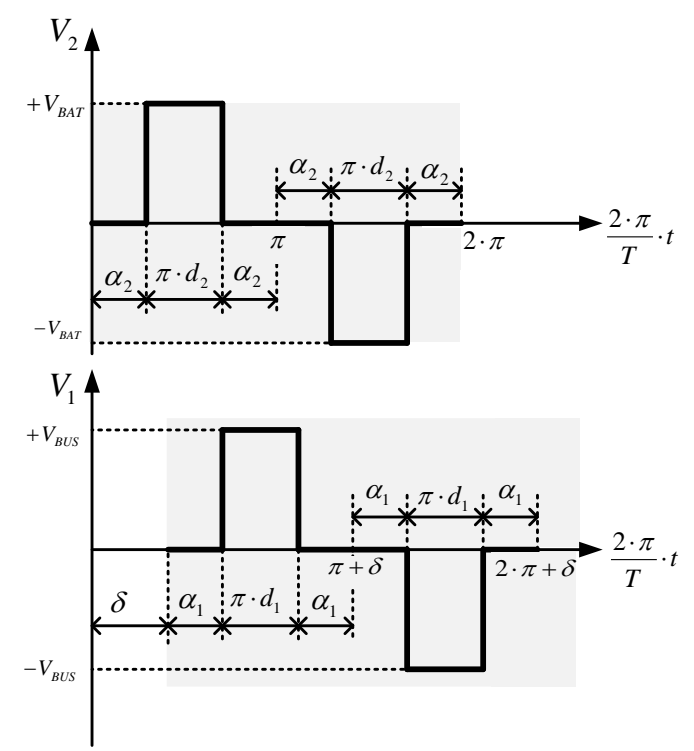

Fig. 4. Typical control waveforms ( $\delta$ positive, energy storage).. 
Different methods of analysis can be found in the literature [2][3], but in this work a Fourier analysis has been conducted in order to establish a design procedure. The Fourier development of $\mathrm{V}_{1}(\mathrm{t})$ is:

$$
V_{1}(t)=\frac{4 \cdot n \cdot V_{B A T}}{\pi} \cdot \sum_{i=0}^{\infty} \frac{1}{2 \cdot i+1} \cdot \cos \left(\frac{\pi}{2} \cdot\left(1-d_{1}\right) \cdot(2 \cdot i+1)\right) \cdot \sin \left(\frac{2 \cdot \pi}{T} \cdot(2 \cdot i+1) \cdot t\right)
$$

The fundamental value of $\mathrm{V}_{1}$ voltage is obtained with $\mathrm{i}=0$ :

$$
V_{1_{-} F}(t)=\frac{4 \cdot n \cdot V_{B A T}}{\pi} \cdot \cos \left(\frac{\pi}{2} \cdot\left(1-d_{1}\right)\right) \cdot \sin \left(\frac{2 \cdot \pi}{T} \cdot t\right)
$$

In the same way, de Fourier development of $\mathrm{V}_{2}(\mathrm{t})$ is:

$$
V_{2}(t)=\frac{4 \cdot V_{B U S}}{\pi} \cdot \sum_{i=0}^{\infty} \frac{1}{2 \cdot i+1} \cdot \cos \left(\frac{\pi}{2} \cdot\left(1-d_{2}\right) \cdot(2 \cdot i+1)\right) \cdot \sin \left(\frac{2 \cdot \pi}{T} \cdot(2 \cdot i+1) \cdot t+\delta \cdot \frac{\pi}{180}\right)
$$

And similarly, the fundamental value of $\mathrm{V}_{2}$ voltage is obtained with $\mathrm{i}=0$ :

$$
V_{2_{-} F}(t)=\frac{4 \cdot V_{B U S}}{\pi} \cdot \cos \left(\frac{\pi}{2} \cdot\left(1-d_{2}\right)\right) \cdot \sin \left(\frac{2 \cdot \pi}{T} \cdot t+\delta \cdot \frac{\pi}{180}\right)
$$

Using a complex representation of each harmonic (denoted using the letter i), the output of each inverter $\left(\mathrm{V}_{1}\right.$ and $\left.\mathrm{V}_{2}\right)$ and the current across the inductor can be easily obtained.

$$
\begin{gathered}
\vec{V}_{1_{-} i}=\frac{4 \cdot n \cdot V_{B A T}}{\pi \cdot(2 \cdot i+1)} \cdot \cos \left(\frac{\pi}{2} \cdot\left(1-d_{1}\right) \cdot(2 \cdot i+1)\right) \\
\vec{V}_{2_{-} i}=\frac{4 \cdot V_{B U S}}{\pi \cdot(2 \cdot i+1)} \cdot \cos \left(\frac{\pi}{2} \cdot\left(1-d_{2}\right) \cdot(2 \cdot i+1)\right) \cdot\left[\cos \left(\delta \cdot \frac{\pi}{180}\right)+j \cdot \sin \left(\delta \cdot \frac{\pi}{180}\right)\right] \\
\vec{I}_{L_{-} i}=\frac{\vec{V}_{1_{-} i}-\vec{V}_{2_{-} i}}{R+j \cdot 2 \cdot \pi \cdot f \cdot(2 \cdot i+1) \cdot L}
\end{gathered}
$$

In the particular case of the fundamental value $(\mathrm{i}=0)$ these expressions can be simplified and they have been presented in equations (8), (9) and (10):

$$
\begin{gathered}
\vec{V}_{1}=\frac{4 \cdot n \cdot V_{B A T}}{\pi} \cdot \cos \left(\frac{\pi}{2} \cdot\left(1-d_{1}\right)\right) \\
\vec{V}_{2}=\frac{4 \cdot V_{B U S}}{\pi} \cdot \cos \left(\frac{\pi}{2} \cdot\left(1-d_{2}\right)\right) \cdot\left[\cos \left(\delta \cdot \frac{\pi}{180}\right)+j \cdot \sin \left(\delta \cdot \frac{\pi}{180}\right)\right]
\end{gathered}
$$




$$
\vec{I}_{L}=\frac{\vec{V}_{1}-\vec{V}_{2}}{R+j \cdot 2 \cdot \pi \cdot f \cdot L}
$$

The active power $(\mathrm{Pi}$ ) and the reactive power (Qi) handled by the converter can be also easily obtained for each harmonic:

$$
\vec{S}_{i}=\frac{\vec{V}_{2 \_i} \cdot \vec{I}_{L_{-} i}}{2}=P_{i}+j \cdot Q_{i}
$$

And from the expression (11) the total active power (P) and the total reactive power (Q) have been obtained and represented in figures 5 and 6.

$$
P=\sum_{i=0}^{\infty} P_{i}
$$

$$
Q=\sum_{i=0}^{\infty} Q_{i}
$$

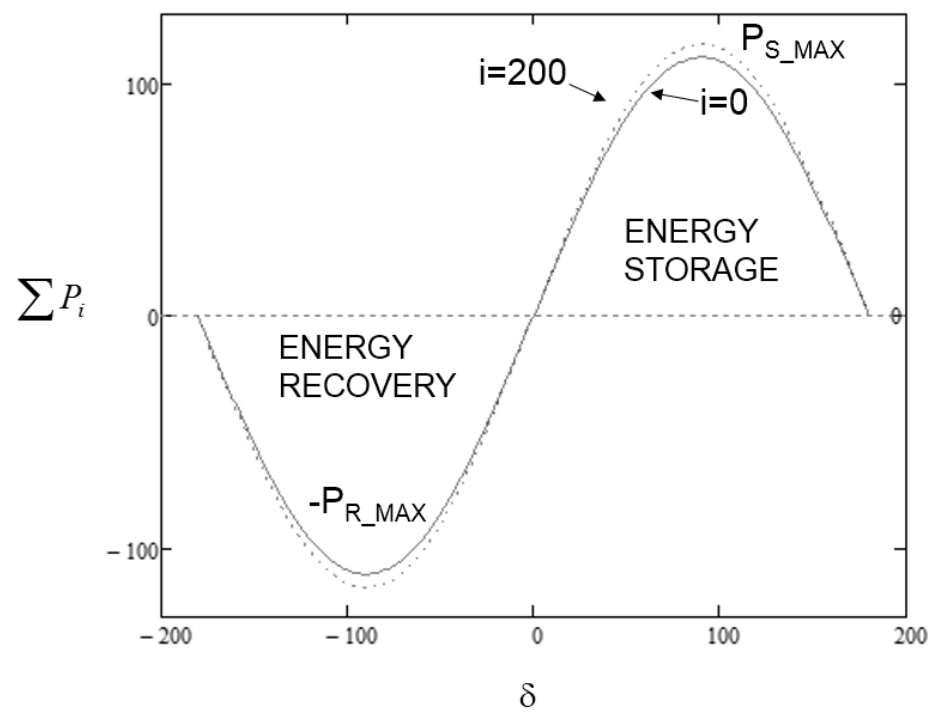

Fig. 5. Power handled by the converter $\left(\sum P_{i}\right)$ using only fundamental $(i=0)$ and 200 Harmonics. $\left(V_{B U S}=24 V, V_{B A T}=12\right.$ $V, f=50 \mathrm{KHz}, n=1, L=10 \mu \mathrm{H}$ and $R=1 \mathrm{~m} \Omega$ )

It is important to emphasize that differences between one design based on fundamental harmonic and another design based on a complete signal is very small. As it is shown in figures 5 and 6 differences in Active Power $(\mathrm{P})$ and Reactive Power $(\mathrm{Q})$ are really small using only fundamental approach or 200 harmonics. Maximum power stored ( $\delta$ positive) or delivered $(\delta$ negative) it is obtained with a phase-shift of $90^{\circ}$ (in advance or delayed). 


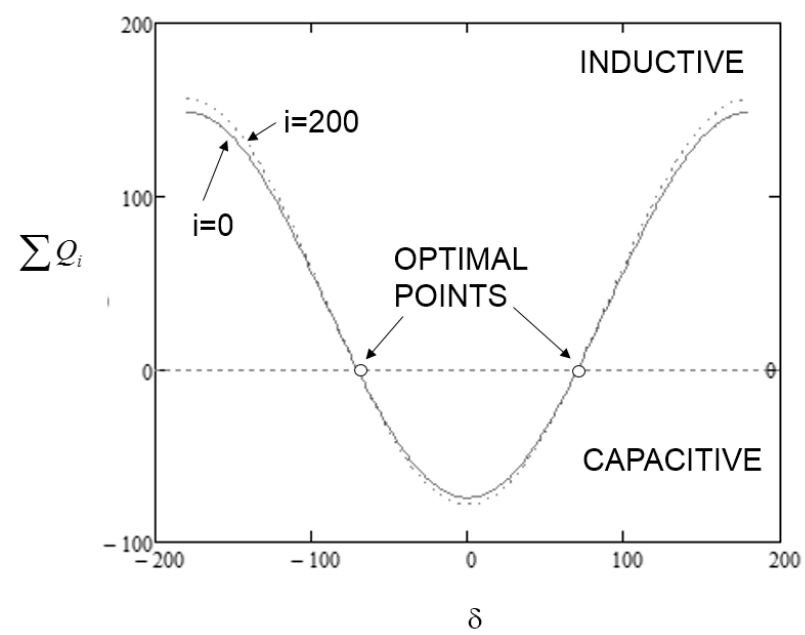

Fig. 6. Reactive Power handled by the converter $\left(\sum Q_{i}\right)$ using only fundamental $(i=0)$ and 200 Harmonics. $\left(V_{B U S}=24 \mathrm{~V}, V_{B A T}=12 \mathrm{~V}, f=50 \mathrm{KHz} n=1, L=10 \mu \mathrm{H}\right.$ and $\left.R=1 \mathrm{~m} \Omega\right)$

On the other hand, the maximum Reactive Power handled by the converter happens with phase-shift values of $0^{\circ}$ (capacitive behavior) and $180^{\circ}$ (Inductive behavior). In the figure 6, optimal points $(\mathrm{Q}=0)$ have been marked. Operation in this points implies an optimal design and it is the goal of this work.

In order to explain the basic operation of this converter, different regions have been graphically presented in the Figure 7. Two vectors $V_{1}$ and $V_{2}$ have been used to represent the output voltage of both inverters. Delay between these vectors is the phase $\delta$. Accessible region of the $\mathrm{DAB}$ converter happens inside the circle of greater voltage $\left(\mathrm{V}_{1}\right.$ in the figure 7$)$.

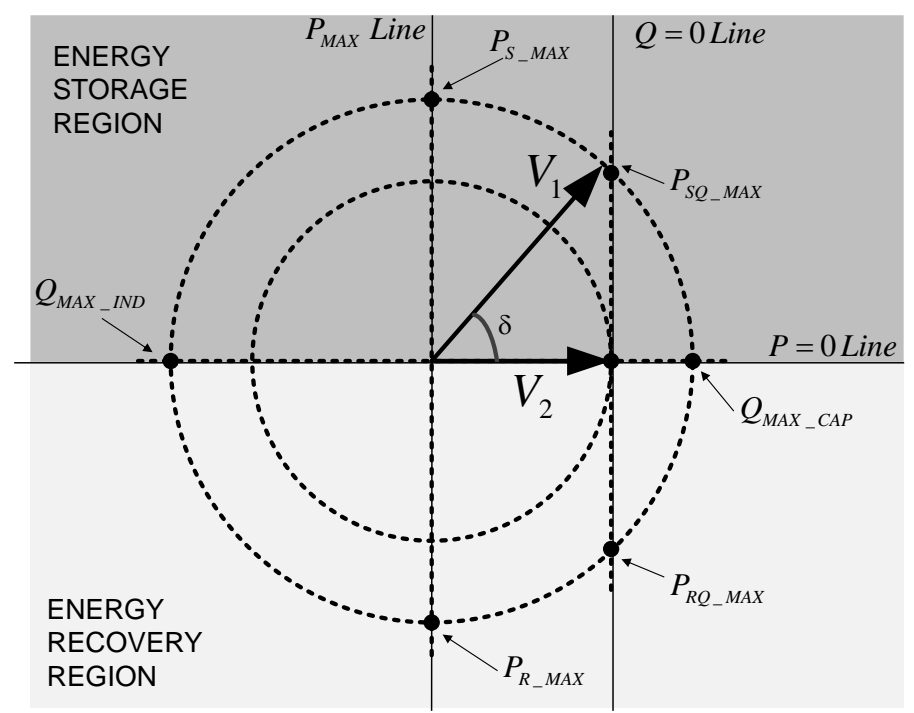

Fig. 7. Operation regions of a DAB converter. 
Energy Storage Region and Energy Delivered Region have been emphasized. Absolute Maximum Power Points (P__MAX and $\mathrm{P}_{\mathrm{R} \_ \text {max }}$ with phase's $\left.\pm 90^{\circ}\right)$ are also indicated in the figure. The Optimal Line $(\mathrm{Q}=0$ Line) divides the operation area in two regions denoted as capacitive and inductive behavior. Assuring operation over Optimal Line, maximum power capability in order to store or recover energy have been indicated in the figure (points $\mathrm{P}_{\mathrm{SQ} \_\mathrm{MAX}}$ and $\mathrm{P}_{\mathrm{RQ} \_m a x}$ ). Both points are fundamental elements in the design proposal included in this paper. Regions are different depending on relative values of $V_{1}$ and $V_{2}$. In any case, in the context of this paper, $\delta$ positive implies $\mathrm{V}_{1}$ in advance with $\mathrm{V}_{2}$.

Operation over the Optimal Line between $\mathrm{P}_{\mathrm{SQ} \_ \text {MAX }}$ and $\mathrm{P}_{\mathrm{RQ} \_ \text {max }}$, implies a quasi-linear relationship between Power (P) and angle $(\delta)$ and this a remarkable consideration.

Taking into account these ideas, two control strategies have been proposed (Linear Phase Droop Control - LPDC and Cosine Phase Droop Control-CPDC) in order to operate over this line.

If $\mathrm{V}_{1}$ is greater than $\mathrm{V}_{2}$, operation over Optimal Line implies not reactive power and Zero Current Switching (ZCS) capability in the Battery Inverter $\left(V_{2}\right)$. See figure 8 for ZCS waveforms in $V_{1}$.

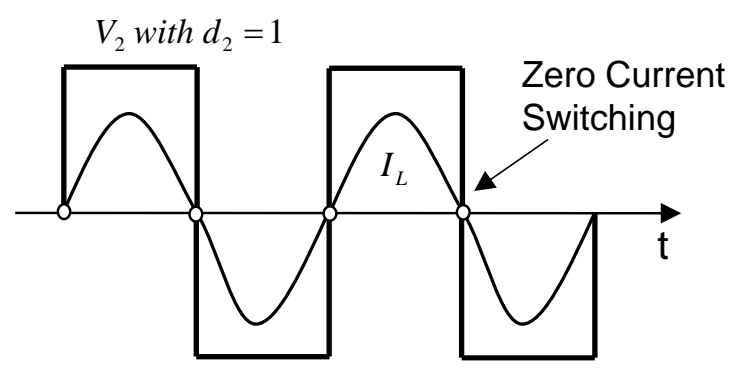

Fig. 8. DAB operation over $Q=0$ line with LPDC or CPDC. Zero Current Switching (ZCS).

Furthermore, If $\mathrm{V}_{2}$ is greater than $\mathrm{V}_{1}$, operation over Optimal Line implies not reactive power and ZCS capability in the DC bus Inverter $\left(\mathrm{V}_{1}\right)$. Depending on the control strategy proposed ZCS can be obtained in battery inverter, in DC bus inverter or in both inverters. 


\section{DESIGN STRATEGY OF DAB CONVERTER AS ENERGY/RECOVERY SYSTEM IN A LIGHTING SMART}

\section{GRID}

Having in mind previous considerations the main design criteria is to assure ZCS in one or in both inverters during the whole operation range, that is to say, with all the operation points over the Optimal Line.

\section{(a).- Linear Phase Droop Control (LPDC) implementation (see Figure 9).}

With LPDC implementation, transformer ratio $n$ must be chosen to assure $V_{1}>V_{2}$ during all the operation region and the duty cycle of $\mathrm{V}_{2}$ voltage has been chosen in order to assure $\mathrm{d}_{2}=1$. With these conditions, ZCS is always possible in the Battery Inverter $\left(\mathrm{V}_{2}\right)$ during energy storage and also energy recovery.

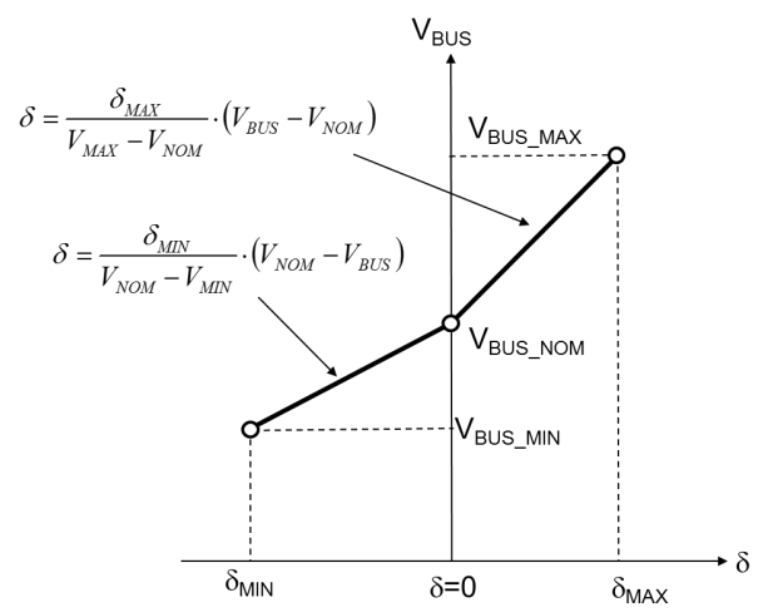

Fig. 9. Linear implementation of LPDC.

LPDC assuring $\mathrm{V}_{2}>\mathrm{V}_{1}$ during all operation region is also possible, in this case ZCS operation happens in the DC Bus Inverter $\left(\mathrm{V}_{1}\right)$. Design of this option is similar to LPDC and it has not been included in this work. With LPDC implementation, a direct relationship between phase angle $(\delta)$ and specified duty cycle $\left(\mathrm{d}_{1}\right.$ value) in $\mathrm{V}_{1}$ inverter (DC bus inverter) exists. See figure 10 for an example. 


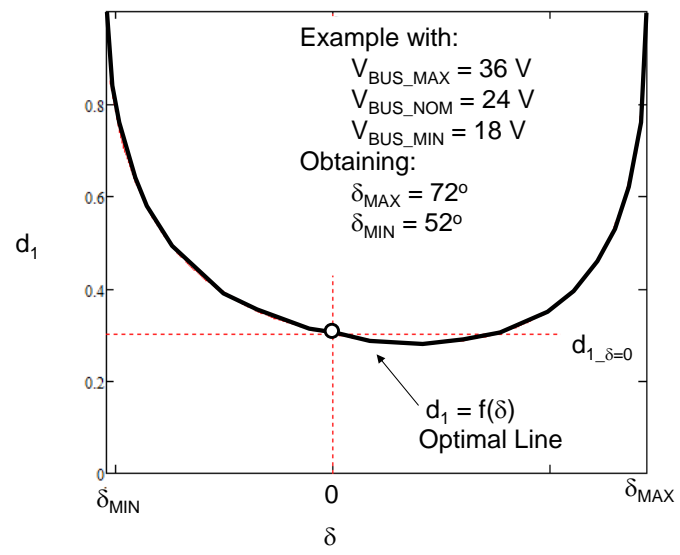

Fig. 10. Example of direct relationship between phase angle $(\delta)$ and specified duty cycle $\left(\mathrm{d}_{1}\right.$ value $)$

Figure 11 shows a DAB converter with LPDC control. A complete regulation system implements an internal control loop with DC bus current regulation and an external current reference obtained from DC bus voltage dependent. Behavior of this converter is excellent but the disadvantage is a complex implementation in the MCU. The advantage is the perfect control of the current extracted or injected to/from the DC bus. A simplified regulation procedure is presented in figure 12. In this case, regulation system is in open loop with phase-shift reference obtained from DC bus voltage. One of the advantages of proposed design is, only $\mathrm{V}_{\mathrm{BUS}}$ will be used to modify the phase $\delta$ (that is to say: $\mathrm{V}_{\mathrm{BUS}}=\mathrm{f}(\delta)$ ) and another advantage it is not current sensing is required in order to implement the control method. Control of the current extracted or injected from/to de DC bus is not perfect, but enough to assure a correct operation of the energy stored/delivered by the system and a perfect equalization of different modules connected to the DC bus.

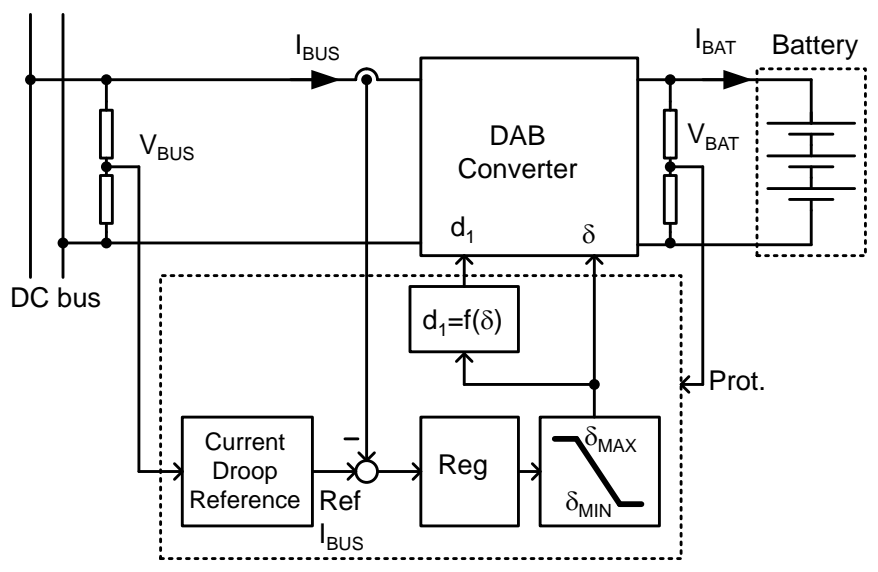

Fig. 11. DAB converter with LPDC control. Regulation system implements an internal control loop with DC bus current regulation and an external current reference obtained from DC bus voltage dependent. 


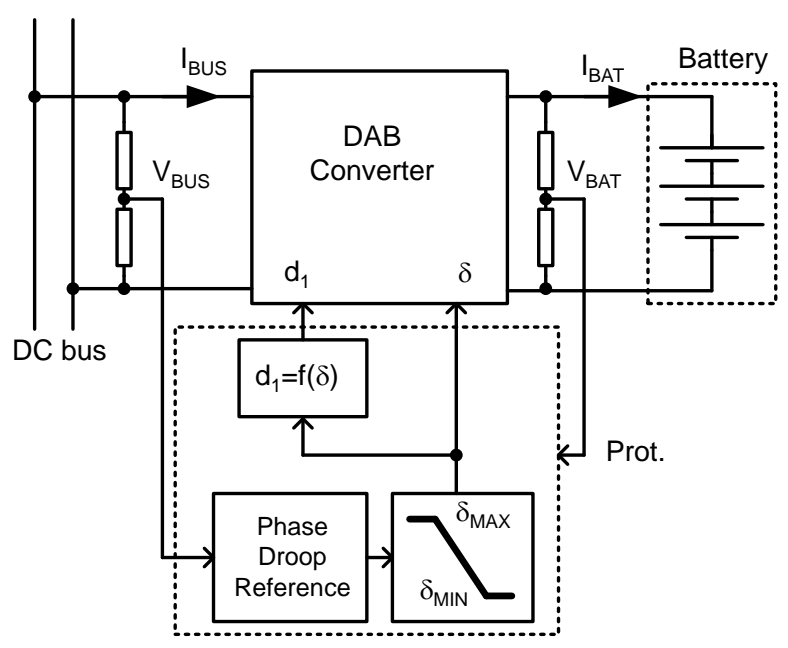

Fig. 12. DAB converter with LPDC control. Regulation system in open loop with phase-shift reference obtained from DC bus voltage.

\section{(b).- Cosine Phase Droop Control (CPDC) implementation (see Figure 13).}

With CPDC implementation, transformer ratio $\mathrm{n}$ must be chosen to assure $\mathrm{V}_{1}=\mathrm{V}_{2}$ with nominal values in DC bus and battery voltage. Then, during energy charging state $V_{1}$ is greater than $V_{2}\left(V_{1}>V_{2}\right)$ and during energy recovery state $V_{2}$ is greater than $\mathrm{V}_{1}\left(\mathrm{~V}_{2}>\mathrm{V}_{1}\right)$. The phase $\delta$ is chosen as a cosine function of DC bus voltage in order to assure operation over the Optimal Line allowing operation always with duty equal 1 in both inverters $\left(\mathrm{d}_{1}\right.$ and $\left.\mathrm{d}_{2}=1\right)$.

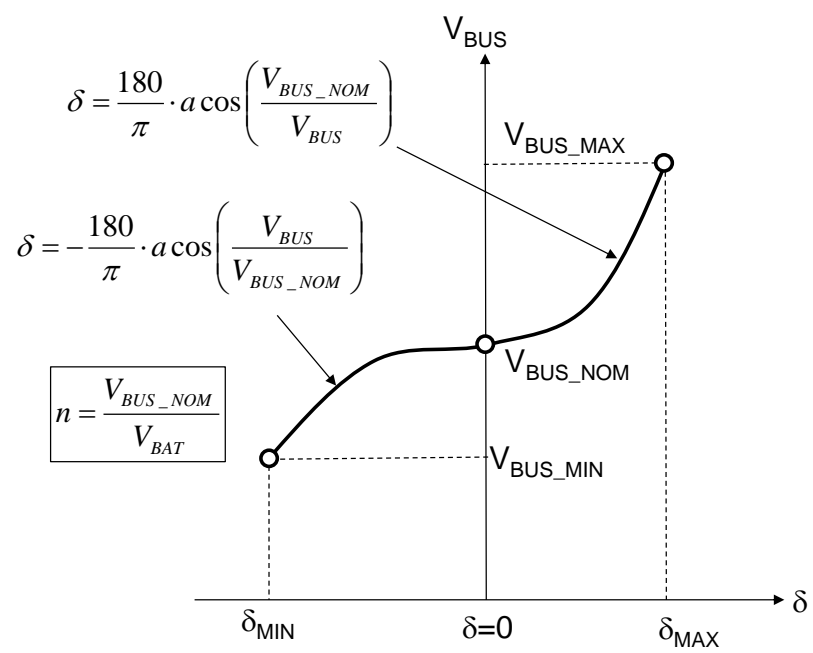

Fig. 13. Cosine implementation of $C P D C$.

Important advantage and simplification of MCU implementation can be obtained using this method. Using the proposed cosine function, obtained from the analysis, ZCS is achieved in battery inverter $\left(V_{2}\right)$ during energy storage $\left(V_{1}>V_{2}\right)$. Similarly, ZCS 
is achieved in the DC bus inverter $\left(\mathrm{V}_{1}\right)$ during energy recovery $\left(\mathrm{V}_{2}>\mathrm{V}_{1}\right)$. In any case, LPDC and CPDC implies $\delta$ value has been adopted as regulation parameter.

\section{(c) Mathematical study of both LPDC and CPDC implementations.}

In both cases mathematically operation over optimal line implies condition presented in equation (14).

$$
\left|\vec{V}_{1}\right| \cdot \cos (\delta)=\left|\vec{V}_{2}\right|
$$

And using fundamental approach, the condition (14) of operation over the optimal line can be obtained and it has been presented in equation (15):

$$
\frac{4 \cdot V_{B U S}}{\pi} \cdot \cos \left[\frac{\pi}{2} \cdot\left(1-d_{1}\right)\right] \cdot \cos \left(\delta \cdot \frac{\pi}{180}\right)=\frac{4 \cdot n \cdot V_{B A T}}{\pi}
$$

In a general situation, the task of obtain the duty cycle value (d1) from this expression is complex, and implies a complex MCU implementation. See figure 10 for an example using equation (15). With CPDC implementation, $d_{1}$ is always 1 in all the operation range.

\section{DESIGN EXAMPLE, EXPERIMENTAL AND SIMULATION VERIFICATION}

An experimental DAB converter with both Linear Phase Droop Control (LPDC) and Cosine Phase Droop Control (CPDC) have been tested and simulated. The main elements of the converters are:

- Inductance (L): $10 \mu \mathrm{H}$ with $\mathrm{Rs}=0.1 \Omega$

- Isolation transformer (1:1). $\mathrm{Lm}=1 \mathrm{mH}, \mathrm{Ld} 1=\mathrm{Ld} 2=0.05 \mathrm{uH}, \mathrm{Rs} 1=\mathrm{Rs} 2=5 \mathrm{~m} \Omega$ (LPDC implementation)

- Isolation transformer (2:1). $\mathrm{Lm}=1 \mathrm{mH}, \mathrm{Ld} 1=0.2 \mathrm{uH}, \mathrm{Ld} 2=0.05 \mathrm{uH}, \mathrm{Rs} 1=20 \mathrm{~m} \Omega, \mathrm{Rs} 2=5 \mathrm{~m} \Omega(\mathrm{CPDC}$ implementation)

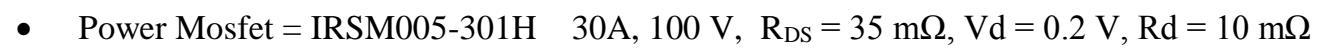

- $\quad$ Switching Frequency $=50 \mathrm{KHz}(\mathrm{T}=20 \mu \mathrm{S})$. Dead Time $=0.2 \mu \mathrm{S}$

- $\mathrm{V}_{\text {BAT }}=12 \mathrm{~V}$ (Voltage Point under test). Lithium batteries of 3.2 V/15 Ah ( $\mathrm{V}_{\text {CELL_MAX }}=3.7 \mathrm{~V}$ and $\mathrm{V}_{\text {CELL_MIN }}=$ $2 \mathrm{~V}$ ) have been used in the final laboratory prototype.

- Bus voltage: $\mathrm{V}_{\text {BUS_MAX }}=36 \mathrm{~V}, \mathrm{~V}_{\text {BUS_NOM }}=24 \mathrm{~V}, \mathrm{~V}_{\text {BUS_MIN }}=18 \mathrm{~V}$.

Using these parameters the next design values have been obtained: 
LPDC operation ( $\mathrm{d}_{2}$ always 1$)$ :

- $\delta_{\mathrm{MAX}}=72^{0}$ (theoretical $\mathrm{P}_{\mathrm{SQ} \_\mathrm{MAX}}=111.5 \mathrm{~W}, \mathrm{~V}_{\mathrm{BUS}}=36 \mathrm{~V}$ with $\mathrm{d}_{1}=1$ ). Maximum Charging Power

- $\delta_{\text {MIN }}=-42^{0}$ (theoretical $P_{\text {RQ_MAX }}=46.2 \mathrm{~W}, \mathrm{~V}_{\text {BUS }}=18 \mathrm{~V}$ with $\mathrm{d}_{1}=1$ ). Maximum Recovering Power

CPDC operation ( $\mathrm{d}_{1}$ and $\mathrm{d}_{2}$ always 1 ):

- $\delta_{\mathrm{MAX}}=48,2^{0}$ (theoretical $\mathrm{P}_{\mathrm{SQ} \_\mathrm{MAX}}=174.7 \mathrm{~W}, \mathrm{~V}_{\mathrm{BUS}}=36 \mathrm{~V}$ ). Maximum Stored Power

- $\delta_{\mathrm{MIN}}=-41.4^{0}$ (theoretical $\mathrm{P}_{\mathrm{RQ} \_\mathrm{MAX}}=-77.5 \mathrm{~W}, \mathrm{~V}_{\mathrm{BUS}}=18 \mathrm{~V}$ ). Maximum Recovered Power

A low cost ARM-based 32-bit MCU from ST (STM32F051R8) will be used in order to implements the control. PWM control will be implemented by software using powerful capabilities of above mentioned MCU. Module IRSM005-301H from IR integrated one leg inverter (two Power MOS of $100 \mathrm{~V}$ and $20 \mathrm{~A}$ ) with all drivers and allowing direct interface with the MCU using $3.3 \mathrm{~V}$ logic levels. Both Power Stages can be easily implemented in a robust way using four IRSM005-301H modules (2 for each inverter).

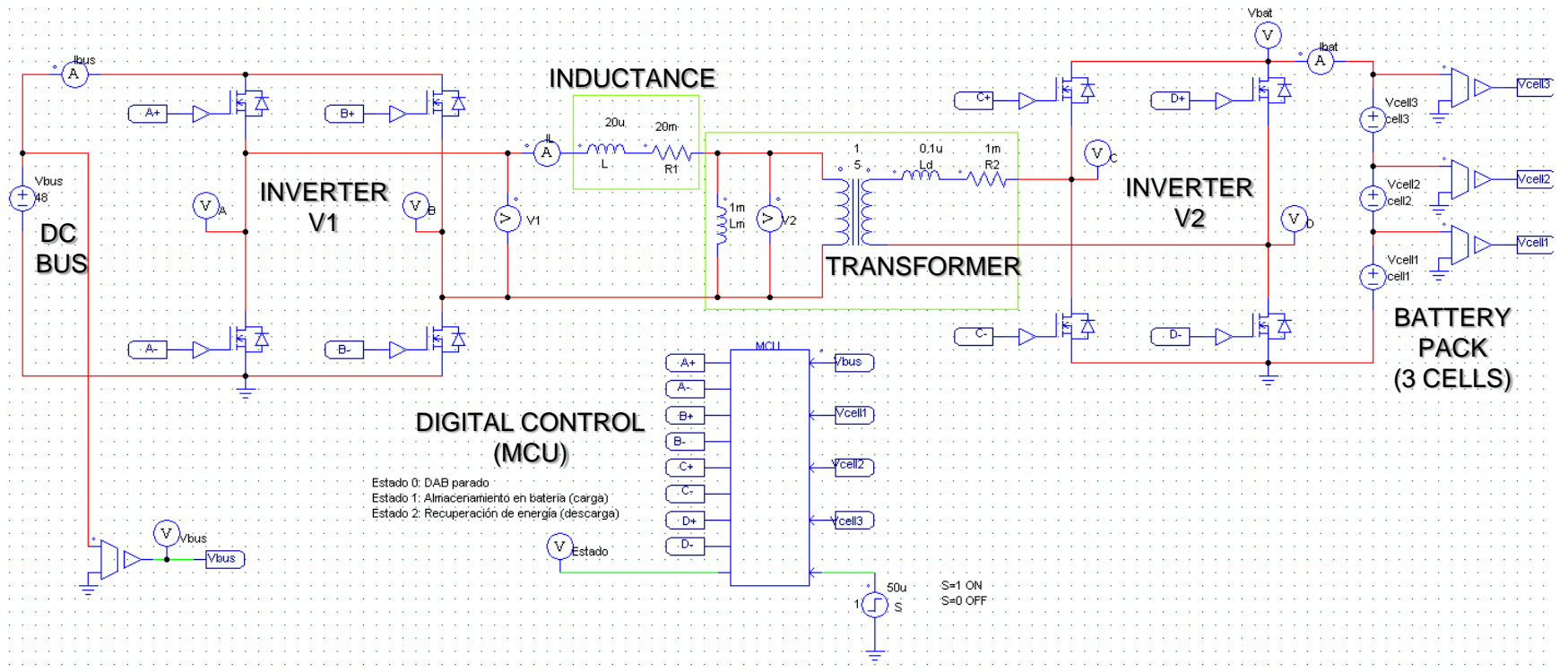

Fig. 14. DAB under test using PSIM. Implementation of Digital Control using C-Block.

Several simulation test using PSIM have been done. Circuit has been simulated using real values obtained over real elements for the lab prototype as a first stage to build a real laboratory prototype. Figure 14 shows PSIM schematic of DAB implementation under test. A digital control using different strategies has been introduced which simulated real operation of ARM-MCU. Conclusions of different test have been included in next sections. 
TEST 1: LPDC implementation in the point of maximum energy storage (maximum value in the DC bus): $\mathrm{V}_{\mathrm{BUS}}=36 \mathrm{~V}$, $\mathrm{V}_{\mathrm{BAT}}=12 \mathrm{~V}$ (see figure 15 for waveforms). $\mathrm{P}_{\mathrm{BUS}}=122.4 \mathrm{~W}, \mathrm{P}_{\mathrm{BAT}}=101.5 \mathrm{~W} \quad \eta=82.9 \%$ (theoretical value $=111.5 \mathrm{~W}$ )

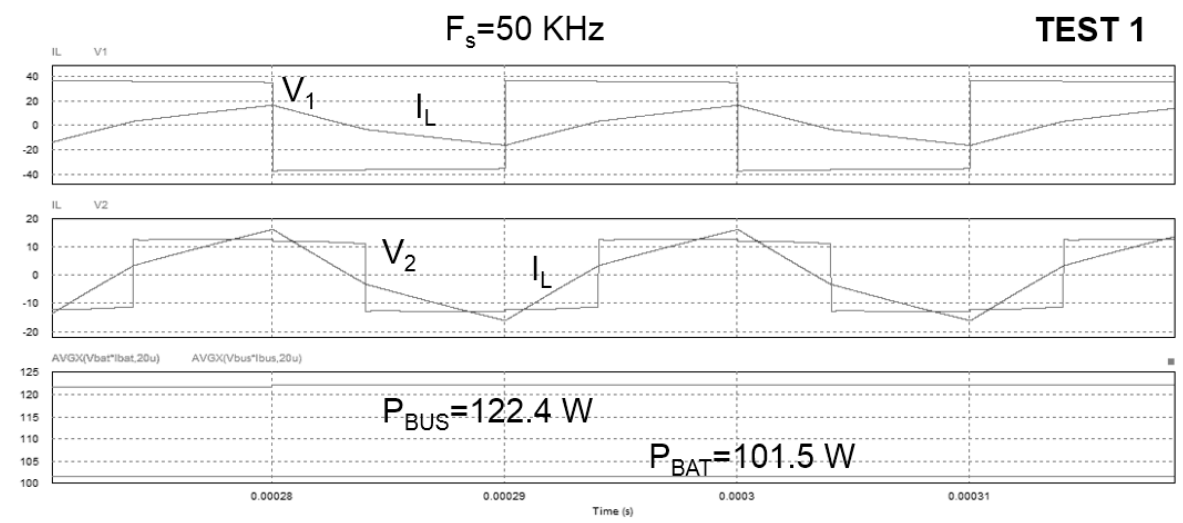

Fig. 15. Test 1 LPDC implementation $\left(V_{B U S}=36 \mathrm{~V}, V_{B A T}=12 \mathrm{~V}, n=1\right)$.

TEST 2: LPDC implementation in the point of maximum energy delivery (lower voltage in the DC bus): $\mathrm{V}_{\mathrm{BUS}}=18 \mathrm{~V}, \mathrm{~V}_{\mathrm{BAT}}=12$ $V$ (see figure 16 for waveforms). $P_{\mathrm{BUS}}=-39.6 \mathrm{~W} \quad \mathrm{P}_{\mathrm{BAT}}=-44.0 \mathrm{~W} \quad \eta=90 \%$ (theoretical value $=46.2 \mathrm{~W}$ )

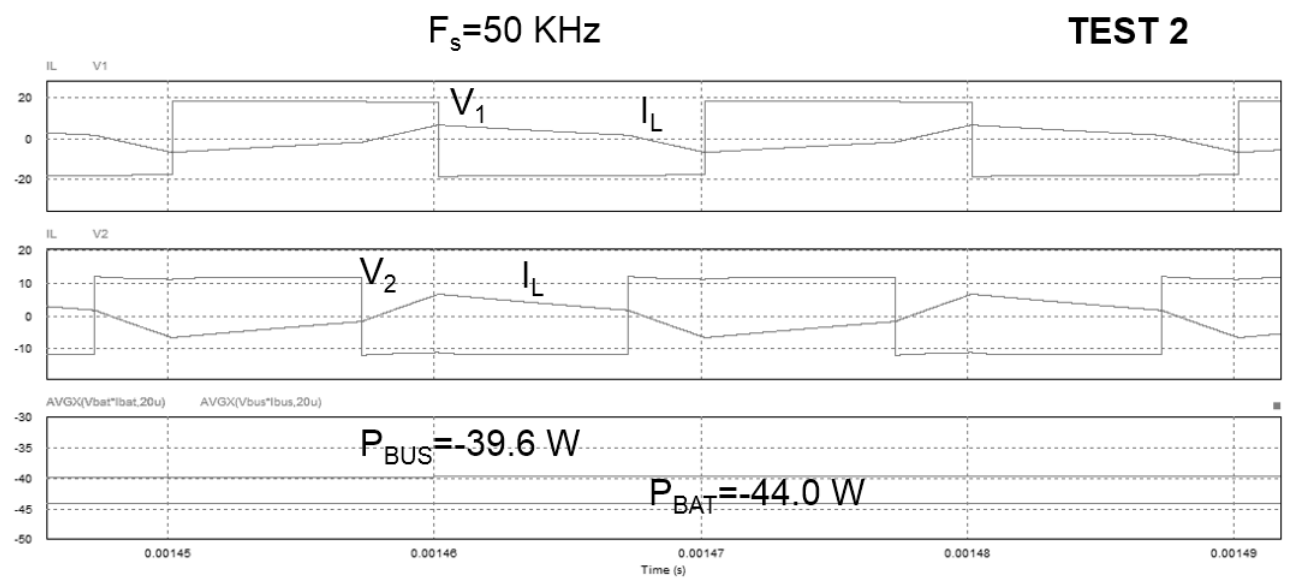

Fig. 16. Test 2 LPDC implementation $\left(V_{B U S}=18 \mathrm{~V}, V_{B A T}=12 \mathrm{~V}, n=1\right)$.

TEST 3: LPDC implementation and point of not power handled (nominal DC bus voltage): $\mathrm{V}_{\mathrm{BUS}}=24 \mathrm{~V}, \mathrm{~V}_{\mathrm{BAT}}=12 \mathrm{~V}$ (see figure 17 for waveforms). $P_{\mathrm{BUS}}=-17.6 \mathrm{~mW}, \mathrm{P}_{\mathrm{BAT}}=-0.38 \mathrm{~W} \quad$ (Theoretical value $=0$ ). 


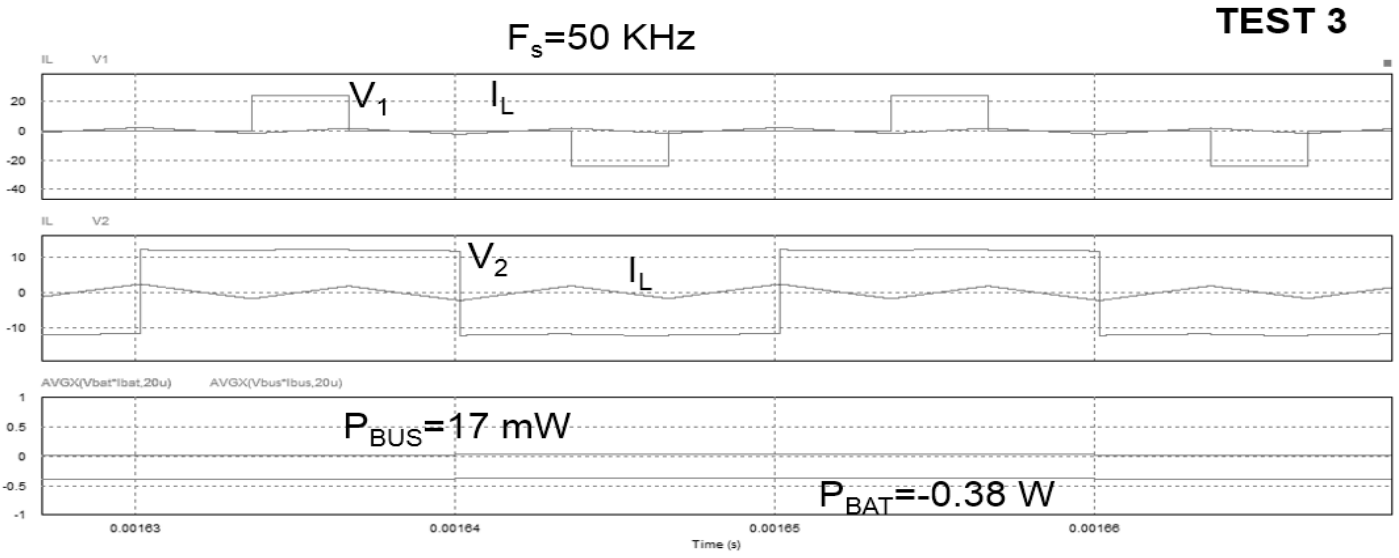

Fig. 17. Test3 LPDC implementation $\left(V_{B U S}=24 \mathrm{~V}, V_{B A T}=12 \mathrm{~V}, n=1\right)$.

TEST 4: CPDC implementation in the point of maximum energy storage (Maximum DC bus voltage): $\mathrm{V}_{\mathrm{BUS}}=36 \mathrm{~V}, \mathrm{~V}_{\mathrm{BAT}}=12$ $\mathrm{V} \mathrm{n}=2$ (see figure 18 for waveforms). $\mathrm{P}_{\mathrm{BUS}}=179.7 \mathrm{~mW} \quad \mathrm{P}_{\mathrm{BAT}}=159.7 \mathrm{~W} \quad \eta=88.8 \%$ (Theoretical value $=174.7 \mathrm{~W}$ )

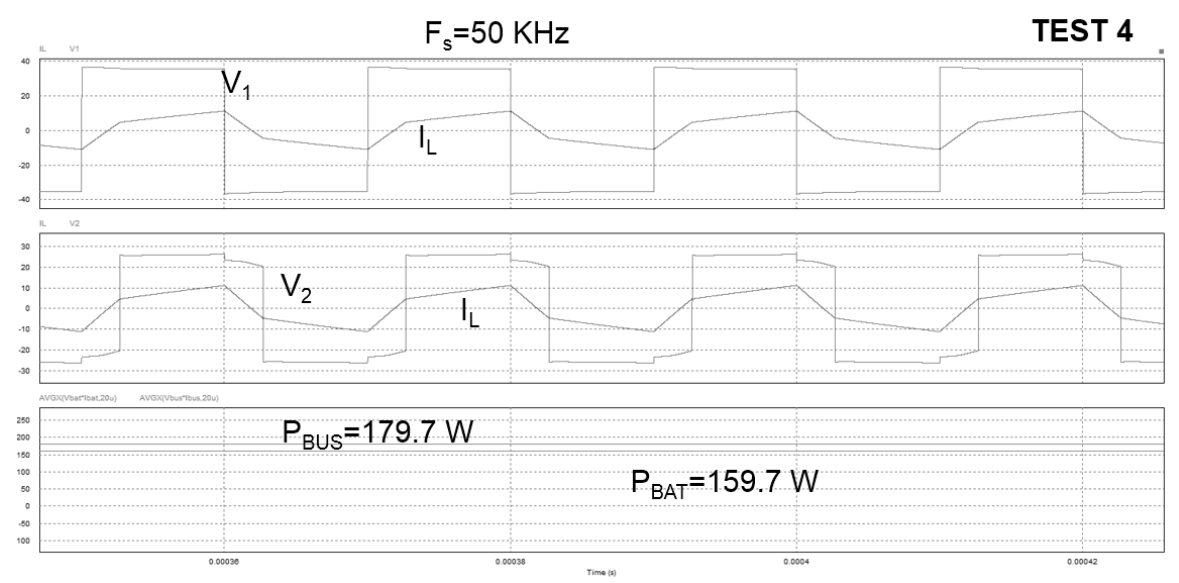

Fig. 18. Test 4 CPDC implementation $\left(V_{B U S}=36 \mathrm{~V}, V_{B A T}=12 \mathrm{~V}, n=2\right)$

TEST 5: CPDC implementation in the point of maximum energy delivery (lower DC bus voltage): $\mathrm{V}_{\mathrm{BUS}}=18 \mathrm{~V}, \mathrm{~V}_{\mathrm{BAT}}=12 \mathrm{~V}$ $\mathrm{n}=2$ (see figure 19 for waveforms). $\mathrm{P}_{\mathrm{Bus}}=-71.6 \mathrm{~W}$

$\mathrm{P}_{\mathrm{BAT}}=-81.5 \mathrm{~W} \quad \eta=87.8 \%$ (Theoretical value $=77.5 \mathrm{~W}$ ) 


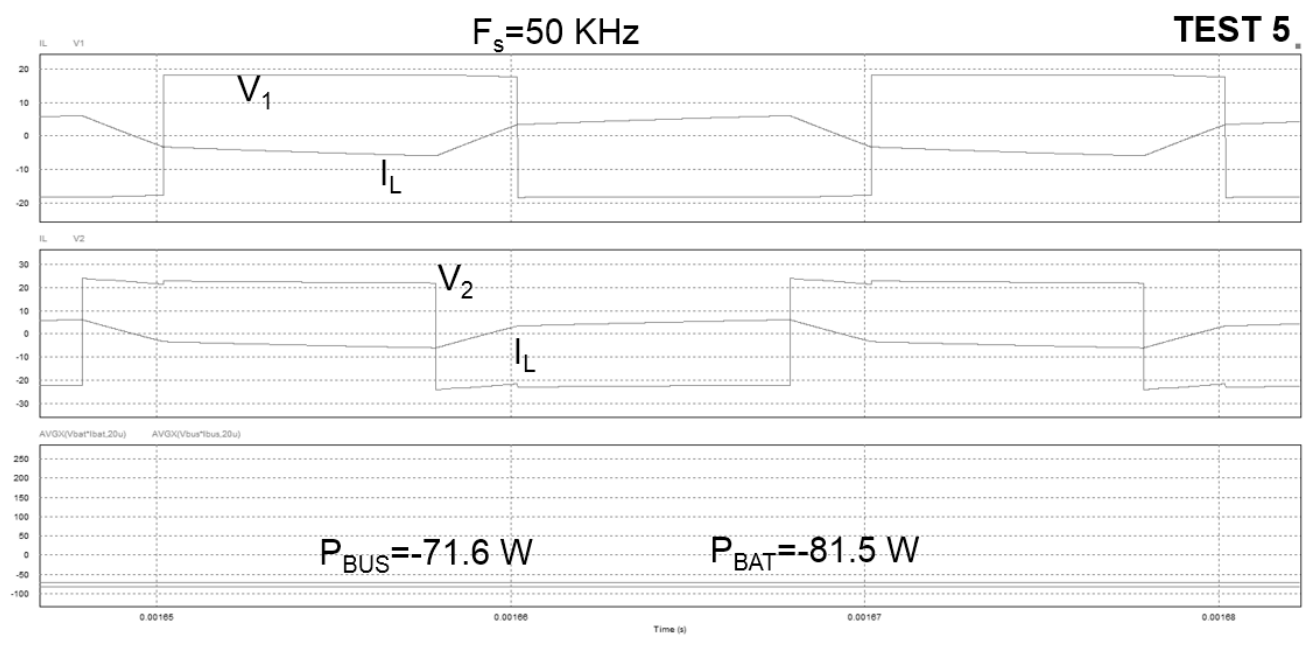

Fig. 19. Test 5 CPDC implementation $\left(V_{B U S}=18 \mathrm{~V}, V_{B A T}=12 \mathrm{~V}, n=2\right)$

TEST 6 : CPDC implementation: Power fluctuations again $200 \mathrm{~Hz}$ fluctuation in DC bus. Test $\mathrm{V}_{\mathrm{BUS}}=24 \pm 5 \mathrm{~V} / 200 \mathrm{~Hz}, \mathrm{~V}_{\mathrm{BAT}}=12$ $\mathrm{V} n=2$ (see figure 20 for waveforms).

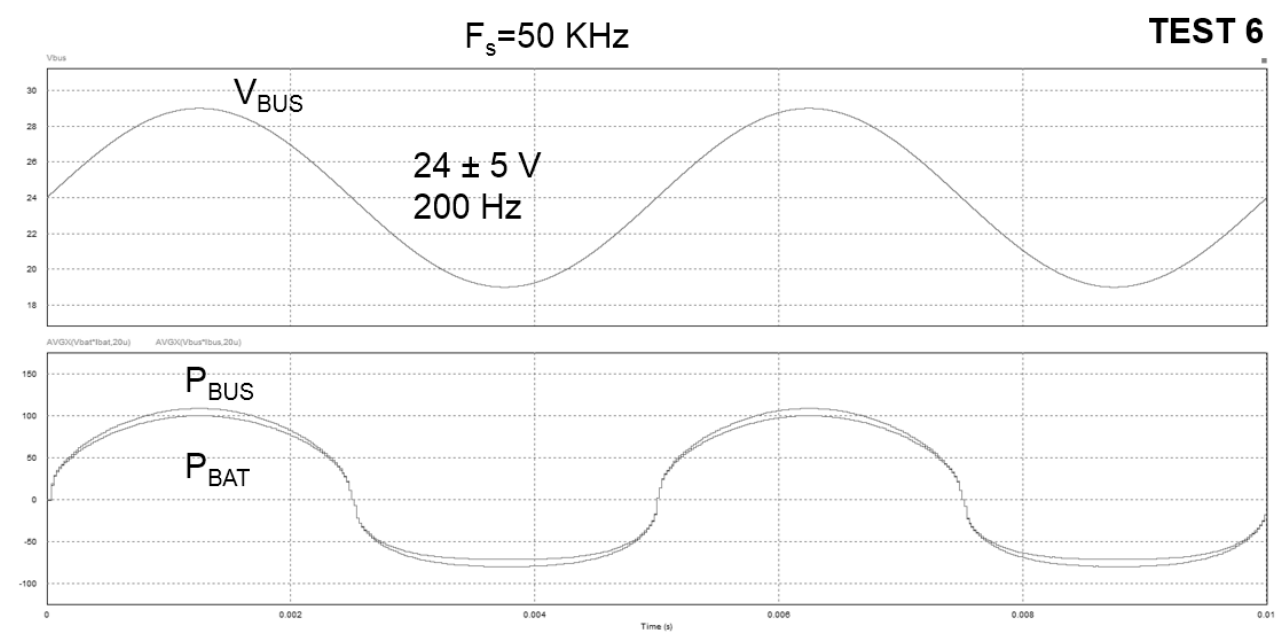

Fig. 20. Test 6 CPDC implementation $\left(V_{B U S}=24 \pm 5 \mathrm{~V} / 200 \mathrm{~Hz}, V_{B A T}=12 \mathrm{~V}, n=2\right)$

TEST 7 : CPDC implementation: Power fluctuation response again $200 \mathrm{~Hz}$ fluctuation in Battery voltage (I). Test $\mathrm{V}_{\text {BAT }}=12 \pm 2$ $\mathrm{V} / 200 \mathrm{~Hz}, \mathrm{~V}_{\mathrm{BUS}}=36 \mathrm{~V} \mathrm{n}=2$ (see figure 21 for waveforms). 


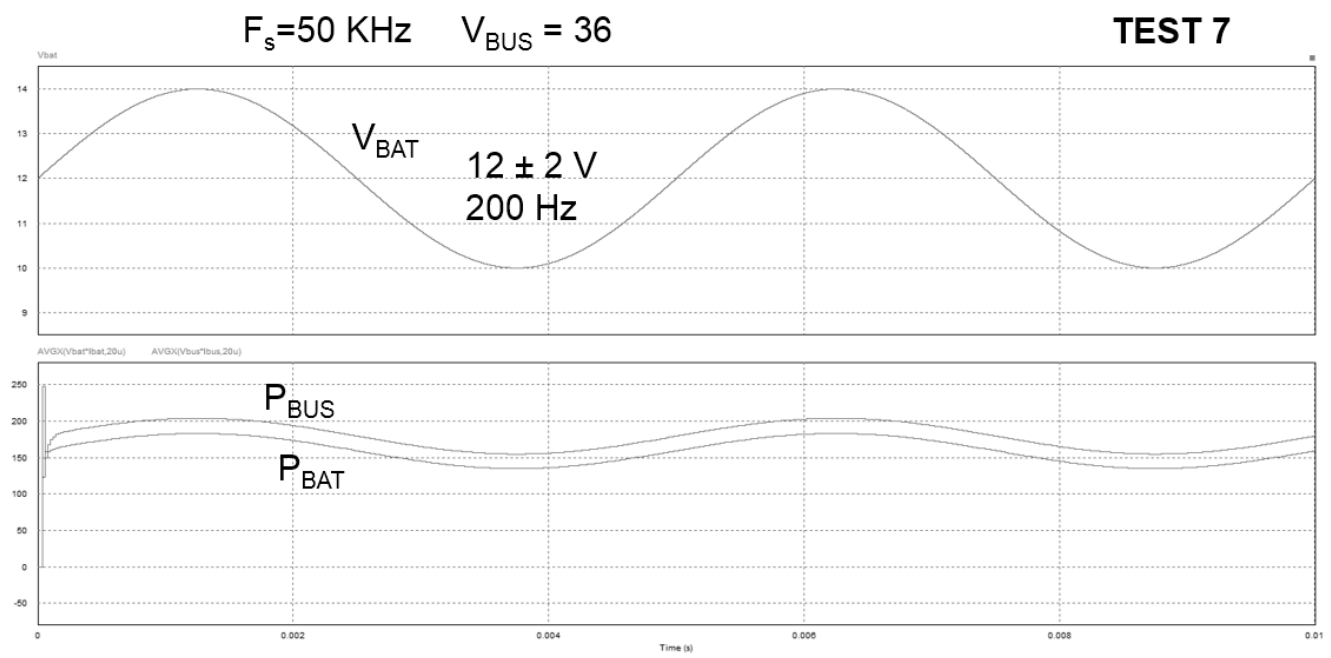

Fig. 21. Test 7 CPDC implementation $\left(V_{B A T}=12 \pm 2 \mathrm{~V} / 200 \mathrm{~Hz}, V_{B U S}=36 \mathrm{~V}, n=2\right)$

TEST 8 : CPDC implementation: Power fluctuation response again $200 \mathrm{~Hz}$ fluctuation in Battery voltage (II). Test $\mathrm{V}_{\mathrm{BAT}}=$ $12 \pm 2 \mathrm{~V} / 200 \mathrm{~Hz}, \mathrm{~V}_{\mathrm{Bus}}=24 \mathrm{~V} \mathrm{n}=2$ (see figure 22 for waveforms).

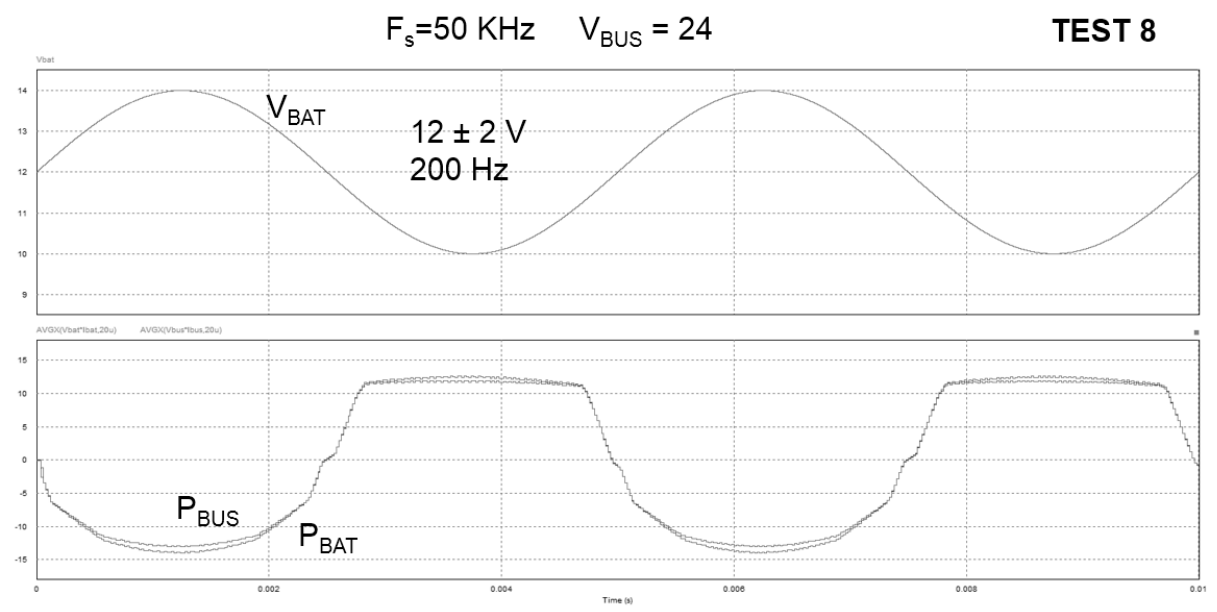

Fig. 22. Test 8 CPDC implementation $\left(V_{B A T}=12 \pm 2 \mathrm{~V} / 200 \mathrm{~Hz}, V_{B U S}=24 \mathrm{~V}, n=2\right)$

TEST 9 : CPDC: Power fluctuation response again $200 \mathrm{~Hz}$ fluctuation in Battery voltage (III). Test $\mathrm{V}_{\mathrm{BAT}}=12 \pm 2 \mathrm{~V} / 200 \mathrm{~Hz}$, $\mathrm{V}_{\mathrm{BUS}}=18 \mathrm{~V} \quad \mathrm{n}=2$ (see figure 23 for waveforms). 


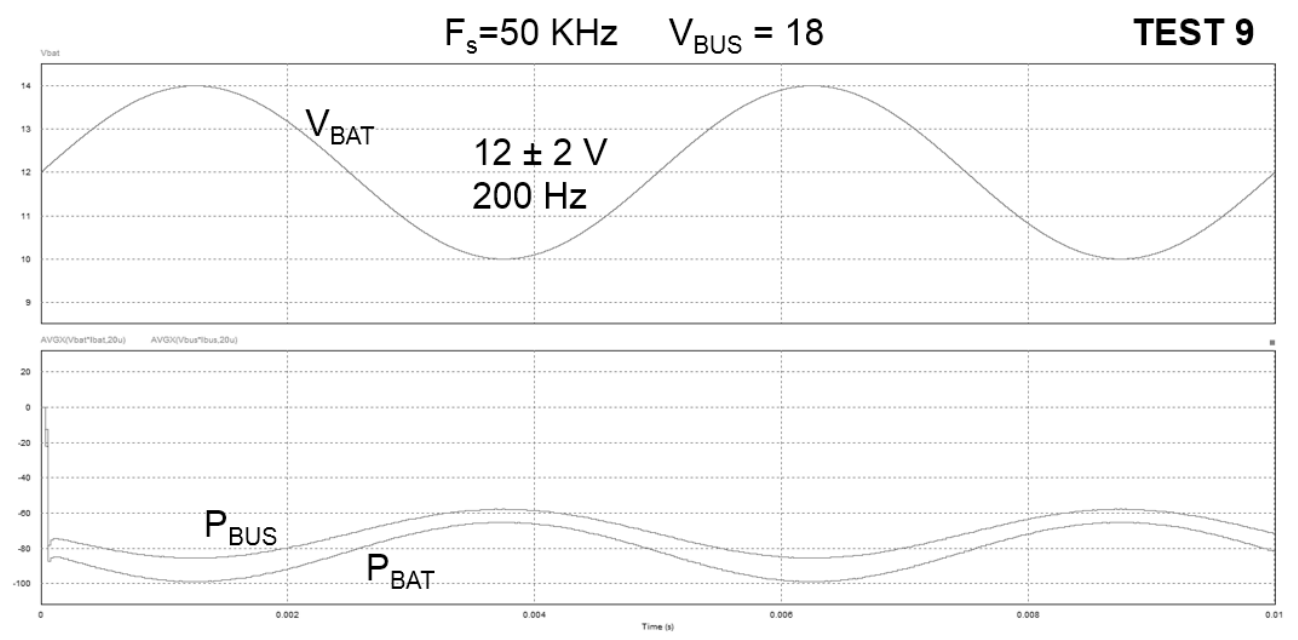

Fig. 23 Test 9 CPDC implementation $\left(V_{B A T}=12 \pm 2 \mathrm{~V} / 200 \mathrm{~Hz}, V_{B U S}=18 \mathrm{~V}, n=2\right)$

Final prototypes will be evaluated over a laboratory Lighting Smart Grid using a renewable energy source with MPPT operation delivering to DC bus a total power of $50 \mathrm{~W}$ and a LED lighting system consuming a power of $30 \mathrm{~W}$. ON/OFF operation in both elements has been verified using DAB converter with Phase Droop Control (PDC).

\section{CONCLUSIONS}

Lighting Systems are suffering and important evolution with introduction of LED lighting capabilities allowing new strategies of energy savings, incorporation of renewable energy sources and optionally a bidirectional interconnection with the mains (AC grid or DC interconnection bus).

Lighting Systems are moving to Lighting Smart Grids a step by step integrating in Smart City strategies. In this context design of modular and efficient energy storage/recovery systems are gaining importance looking for future applications and new services.

This work evaluates the use of Dual-Active Bridge (DAB) as energy storage/recovery system thinking in the context of a Lighting Smart Grid. A complete study of this converters, design procedure in order to operate over the Optimal Line (no reactive power) and two simplified control strategies (Linear Phase Droop Control - LPDC and Cosine Phase Droop Control - LPDC) have been proposed, offering robust, modular and self-equalization performances. 


\section{REFERENCES}

[1]. M. Jaureguizar, D. Garcia-Llera, M. Rico-Secades, A.J. Calleja, E.L. Corominas. "Enerlight project: Walking from electronic lighting systems to Lighting Smart Grid”. IEEE SmartMILE Conference. December 2013. DOI:

10.1109/SmartMILE.2013.6708166

[2]. D. S. Segaran. "Dynamic Modelling and Control of Dual Active Bridge Bi-directional DC-DC Converters for Smart Grid Applications". PhD work. School of Electrical and Computer Engineering (SECE), RMIT University. February 7, 2013 DOI:

[3]. X. Lu, J. M. Guerrero, K. Sun, Member, J. C. Vasquez. “An Improved Droop Control Method for DC Microgrids Based on Low Bandwidth Communication with DC Bus Voltage Restoration and Enhanced Current Sharing Accuracy” IEEE trans. On Power Electronics, VOL. 29, NO. 4, APRIL 2014. DOI: 10.1109/TPEL.2013.2266419

[4]. L. Roggia1, F. Beltrame, L. Schuch1, J. R. Pinheiro. "Comparison between Full-Bridge-Forward Converter and DAB Converter”. Power Electronics Conference (COBEP), 2013 Brazilian. Date 27-31 Oct. 2013. DOI:

[5]. F. Krismer, J. W. Kolar. "Closed Form Solution for Minimum Conduction Loss Modulation of DAB Converters”. IEEE trans. on Power Electronics, VOL. 27, NO. 1, January 2012. DOI: 10.1109/TPEL.2011.2157976

[6]. J. Everts, F. Krismer, J. Van den Keybus, J. Driesen, J. W. Kolar. “Optimal ZVS Modulation of Single-Phase Single-Stage Bidirectional DAB AC-DC Converters". IEEE trans. on Power Electronics, VOL. 29, NO. 8, August 2014. DOI: 10.1109/TPEL.2013.2292026

[7]. S.-Ch. Lo, S. Yat-sen, Y.-Ch. Wu, T.-L- Lee. "Design and Implementation of a Bidirectional Isolated DAB-Based DC/DC Converter in Home Area Networks”. IEEE Energy Conversion Congress and Exposition (ECCE-2011). Date 17-22 Sept. 2011. DOI: 10.1109/ECCE.2011.6064208

[8]. Oggier, G.G.; Garcia, G.O.; Oliva, A.R., "Switching Control Strategy to Minimize Dual Active Bridge Converter Losses" Power Electronics, IEEE Transactions on , vol.24, no.7, pp.1826,1838, July 2009. DOI: 10.1109/TPEL.2009.2020902

[9]. Oggier, G.G.; Garcia, G.O.; Oliva, A.R., "Modulation strategy to operate the dual active bridge DC-DC converter under soft switching in the whole operating range" Power Electronics, IEEE Transactions on , vol.26, no.4, pp.1228,1236, April 2011. DOI: 10.1109/TPEL.2010.2072966

[10].Everts, J.; Krismer, F.; Van den Keybus, J.; Driesen, J.; Kolar, J.W., "Optimal ZVS Modulation of Single-Phase Single-Stage Bidirectional DAB AC-DC Converters" Power Electronics, IEEE Transactions on , vol.29, no.8, pp.3954,3970, Aug. 2014. DOI: 10.1109/TPEL.2013.2292026

[11].Krismer, F.; Kolar, J.W., "Closed Form Solution for Minimum Conduction Loss Modulation of DAB Converters" Power Electronics, IEEE Transactions on , vol.27, no.1, pp.174,188, Jan. 2012. DOI: 10.1109/TPEL.2011.2157976

[12].Escandon-Lopez, Javier; Moro-Perez-Gonzalo. “Charge System for EVs”. Workrooms Journal. Issue 1. Volume 1. July 2013 DOI: 10.15592/workrooms.2013.0004 
[13].PSIM simulation software. http://powersimtech.com/products/psim/.

[14]. Escandon-Lopez, Javier. "Cargador domestico para vehículos eléctricos con suavizador de curvas de potencia basado en energías renovables “. Trabajo Fin de Grado. Ingeniería Electrónica Industrial y Automática. EPI-Gijon-Spain. Code: 613089. July 2014.

[15]. STMicroelectronics. Datasheets STM32F051xx. "ARM-based 32-bit MCU, 16 to 64-KB Flash, timers, ADC, DAC and communication interfaces, 2.0-3.6 V”. January 2014. Reference: DoclD022265 Rev 4. Webpage: www.st.com

[16]. Escandon, Javier. "Home charge system for EVs with peak power smoothing based on renewable energy". IEEE SmartMILE 2013. ISBN: 978-1-4799-2911-5 December 2013. DOI: 10.1109/SmartMILE.2013.6708186. 